\title{
Left Main Spontaneous Coronary Artery Dissection: The Complexity of Management Considerations
}

\author{
Nachiket Patel ${ }^{1}$ and Timothy E Paterick ${ }^{2 *}$ \\ ${ }^{1}$ Banner Medical Center Phoenix, USA \\ ${ }^{2}$ Aurora Medical Center Green Bay, USA \\ Submission: May 24, 2018; Published: August 07, 2018 \\ *Corresponding author: Timothy E Paterick, Aurora Medical Center Green Bay, USA; Email: tpaterick@gmail.com
}

\begin{abstract}
Spontaneous coronary artery dissection (SCAD) is a rare, complex clinical entity that is often a diagnostic dilemma. Additionally, SCAD is often encased in uncertainty in terms of the optimal therapeutic approach. We present a challenging case of left main coronary artery dissection outlining how clinical presentation; angiographic features of the dissection, and the degree of obstruction to flow delineate the best clinical approach.

Abrrevations: ED: Emergency Department; CABP: Coronary Artery Bypass; LAD: Left Anterior Descending; LM: Left Main; RCA: Right Coronary; CF: Artery Circumflex; IABP: Intra-Aortic Balloon Pump; LIMA: Left Internal Mammary Artery; SV: Saphenous Vein; SCAD: Spontaneous Coronary Artery Dissection; PCI: Percutaneous Coronary Intervention; FMD: Fibro Muscular Dysplasia
\end{abstract}

\section{Case Presentation}

41-year old white female presented to the Emergency Department (ED) with sudden onset, sub-sternal chest pressure, which she characterized as $10 / 10$, radiating to her upper back. She experienced associated nausea and diaphoresis. She

was vacuuming the living room at her home when symptoms developed. The patient's only risk factor was cigarette smoking 1ppd. Her initial ECG showed sinus rhythm with ST-segment elevation in lead aVR, with reciprocal ST-segment depression in the anterior and inferior leads (Figure 1).

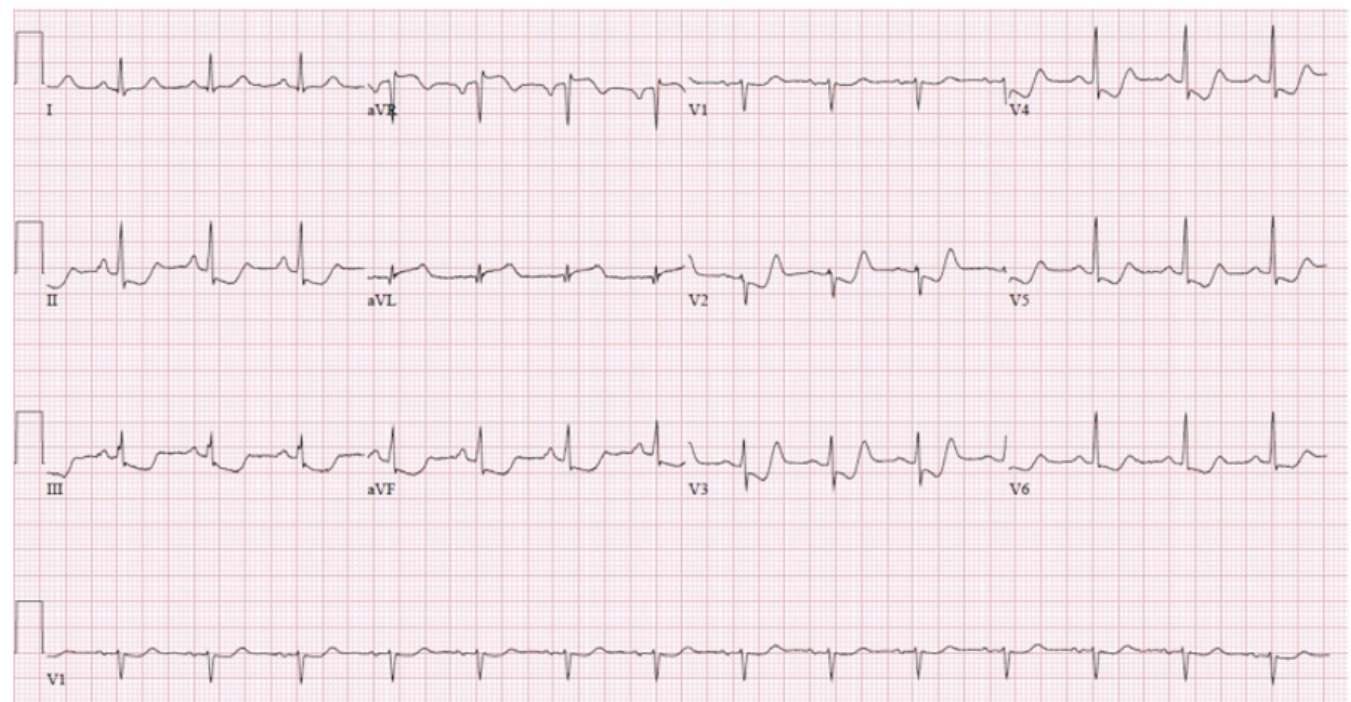

Figure 1: Sinus rhythm with ST-segment elevation in lead aVR, with reciprocal ST-segment depression in the anterior and inferior leads.

She was given 2 sublingual nitroglycerin tablets in the ED with resolution of her symptoms. Her ST segment ECG changes normalized in the ED, but sinus tachycardia persisted. Her point of care troponin was elevated at $23.8 \mathrm{ng} / \mathrm{mL}$. (Normal range: $0.0-$ $0.23 \mathrm{ng} / \mathrm{mL}$ ) Her other lab tests, including her CBC and CMP, were normal. She was hemodynamically stable, with blood pressure of 140/80, and her cardiac physical examination was normal. A stat echocardiogram revealed preserved left ventricular [LV] function without regional wall motion or valvular abnormalities. Doppler data revealed elevated LV filling pressure. She was taken 
urgently for cardiac catheterization. Coronary angiogram showed a dissection flap of the proximal Left Main [LM] coronary artery and a 50\% distal stenosis with TIMI 2 flow. The Left Anterior Descending [LAD], Right Coronary Artery [RCA], and Circumflex $[\mathrm{CF}]$ arteries were angiographically normal.

Post catheterization the patient was symptom free and hemodynamically stable. The clinical team's decision was to observe the patient. The patient remained stable and a decision was made to repeat the cardiac catheterization three days after initial presentation. The angiogram revealed no change in the LM dissection, and there was persistent $50 \%$ obstruction with TIMI 2 flow. The interventional cardiologist decided the LM stenting was high risk and cardiovascular surgery was consulted. The next day while waiting for Coronary Artery Bypass (CABG) she became hemodynamically unstable and developed pulmonary edema. The ECG revealed ST depression inferiorly and laterally. She had emergent Intra-Aortic Balloon Pump (IABP) placement and $C A B G$ with a Left Internal Mammary Artery (LIMA) to the LAD, and Saphenous Vein (SV) grafts to the ramus artery and left CF. Post operatively she experienced bleeding and returned to the operating room for exploration where a vein was clipped at a leak site.

Post op echocardiogram revealed depressed ejection fraction (LVEF of 25\%). There was diffuse hypokinesis of all regional segments of the LV and a large apical filling defect consistent with LV apical thrombus. She remained in the hospital for 14 days post op. The patient returned to the hospital in two weeks with recurrent chest pain. Contrast echocardiography revealed resolution of the apical clot. Repeat angiography revealed the grafts were occluded. The patient was referred to another medical center for LM stenting.

\section{Discussion}

Spontaneous Coronary Artery Dissection (SCAD) is a rare condition identified in a myriad of case reports and retrospective studies. Most publications cite its incidence to be approximately $0.2 \%-1.1 \%$ [1]. It is relatively well known, at this point in time, as a rare condition that mostly affects women in their third through fourth decades of life [1-4]. The incidence of SCAD seems to be higher in Caucasian women [3,5]. Several studies havereported increased frequency in peripartum women [4]. Despite being relatively well characterized from an epidemiological standpoint, several questions remain regarding the disease processes' pathophysiology, risk factors, and optimal definitive management.

Some investigators have suggested SCAD's pathophysiology is related to hematoma formation in the vessel wall. This can occur in the wall of the media, or between the media and adventitia [6,7]. Subsequent expansion of this arterial space can compromise the true lumen and eventually lead to myocardial ischemia. However, many other mechanisms have been implicated ranging from intimal tears to alterations in collagen synthesis [8]. The exact pathophysiology remains an enigma.

The most common association identified in the literature is the association between SCAD and peripartum patients [24]. Studies have identified an incidence of SCAD in peripartum patients ranging from $30-48 \%$ [2,4]. A lack of traditional risk factors for Coronary Artery Disease (CAD) has also been shown to be common in patients diagnosed with SCAD [1-4]. Of traditional CAD risk factors, smoking and hypertension were most commonly identified $[4,5]$.

Saw et al. identified Fibromuscular Dysplasia (FMD) as a possible predisposing condition to SCAD. In their study, they found that $86 \%$ of their cohort had FMD in greater than or equal to one non-coronary territory. Non-coronary vascular territory was defined as renal, iliac or cerebrovascular. Even more, $42 \%$ had FMD in greater than two non-coronary vascular territories, suggesting that perhaps clinicians should have increased suspicion of SCAD in these patients.

Identifying unique presenting clinical features and symptomology of patient's eventually diagnosed with SCAD remains of the utmost importance for providers who first encounter such patients. Unfortunately, an overwhelming majority of this patient population presents with symptoms typical of Acute Coronary Syndrome (chest pain, arm pain, SOB). They also typically present with elevated cardiac markers [1-5]. This serves to be particularly challenging as it limits clinicians' ability to make the diagnosis clinically.

The diagnosis of SCAD can be made in a number of objective ways. A few methods include coronary angiography, CT angiography, optical coherence tomography, and Intravascular Ultrasound (IVUS) [6]. Once diagnosed, SCAD can be further classified into Types I-III. Classification is based on extent of coronary artery involvement, severity of artery stenosis, and presence of intramural hematoma [5,6].

Numerous of studies have sought to determine optimal management for SCAD, however, the consensus remains that there is no definitive superior treatment. At the most basic level, treatment approach varies between medical management and invasive therapies, specifically Percutaneous Coronary Intervention (PCI) and CABG. Several studies suggest that a conservative approach with close follow-up is superior for stable, non-obstructive lesions [9-11]. There is also evidence to suggest that a more aggressive approach (revascularization) is favorable in the setting of ischemia [11]. Ultimately, each of these studies reaches the same conclusion: more data is needed to confidently recommend a particular treatment modality. Overall, the LAD is affected in $75 \%$ of cases, the RCA in $20 \%$ of cases, CF in $4 \%$ of cases, and the left main coronary artery in $<1 \%$ of cases [12-16].

Revascularization for SCAD is warranted in those patients who present with ongoing ischemia refractory to medical treatment. Cases of spontaneous left main dissections reported in the literature have mainly been treated with $\mathrm{CABG}$, [2-7] especially those with RCA involvement 15 and triple-vessel CAD.16 Successful revascularization with percutaneous stenting has also been described. [17-19]. In cases of severe heart failure, bridging 
to orthotopic heart transplantation with a Left Ventricular Assist Device (LVAD) may be the only option.

\section{Conclusion}

This case represents aclassicexample of the clinical quandaries associated with LM SCAD. This patient presented with hemodynamic instability, a significant LM dissection, a 50\% LM luminal obstruction, diminished coronary flow, and evidence of ischemia as manifest by the biomarkers. Classification based on extent of coronary artery involvement, severity of artery stenosis, and presence of intramural hematoma suggests this represents a class 2-3 dissection. In this circumstance theclinician must determine the best approach to treatment in light of the clinical presentation, the complexity of coronary anatomy, evidence of ischemia, and the skill of the interventional team. In this case the unstable nature of the presentation with ischemia (ECG and biomarkers) and the complexity of the LM dissection suggested the need for "timely" intervention. The normal native coronary arteries raised a concern for graft closure due to competitive flow. In retrospect, the best approach would have been immediate LM stenting by an experienced interventional cardiologist. This case highlights the complex decision making associated with the therapeutic approach to LM SCAD.

\section{References}

1. Patnaik AN, Rao DS (2005) Spontaneous dissection of coronary arteries. Indian Heart J 57: 350-352.

2. Auer J, Punzengruber C, Berent R, Weber T, Lamm G, et al. (2004) Spontaneous coronary artery dissection involving the left main stem: Assessment by intravascular ultrasound. Heart 90(7): e39-e41.

3. Almeda FQ Barkatullah S, Kavinsky CJ (2004) Spontaneous coronary artery dissection. Clin Cardiol 27(7): 377-380.

4. Thistlethwaite PA, Tarazi RY, Giordano FJ, Jamieson SW (1998) Surgical management of spontaneous left main coronary artery dissection. Ann Thorac Surg 66(1): 258-260.

5. Justice LT, Dauterman K, Smedira NG, Moliterno DJ (2005) Left main dissection and thrombosis in a young athlete. Cardiol in Review 13(5): 260-262.

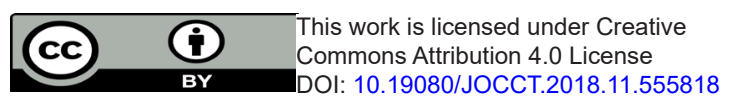

6. Lin TH, Lee KT, Chiu CC, Lai WT, Lin YY, et al. (2003) Spontaneous left main coronary artery dissection: A case report. Kaohsiung J Med Sci 19(9): 476-480.

7. Sajja LR, Farooqi A, Yarlagadda RB, Shaik MS, Pothineni RB (2000) Spontaneous dissection of left main coronary artery: Surgical management. Asian Cardiovasc Thorac Ann 8: 54-55.

8. Mieghem CAGV, Ligthart JMR, Cademartiri F (2006) Spontaneous dissection of the left main coronary artery in a patient with OslerWeber-Rendu disease. Heart 92(3): 394.

9. Najaf SM, Quraishi AR, Kazmi KA (2005) Spontaneous multivessel coronary artery dissection associated with elevated homocysteine levels. J Coll Physicians \& Surgeons Parkistan 15(2): 108-109.

10. Bilato C, Rinuncini M, Roncon L, Zonzin P (2003) Natural evolution of spontaneous multiple coronary dissections causing acute myocardial infarction. Ital Heart J 4(1): 69-70.

11. Zupan I, Noc M, Trinkaus D, Popovic M (2001) Double vessel extension of spontaneous left main coronary dissection in young women treated with thrombolytics. Catheter Cardiovasc Interv 52(1): 226-230.

12. Leclercq F, Messner Pellenc P, Carabasse D, Lucke N, Rivalland F, et al. (1996) Successful thrombolysis treatment of a spontaneous left main coronary artery dissection without subsequent surgery. Eur Heart J 17(2): 320-321.

13. Shroff G, Rajani R (2003) Spontaneous coronary artery dissection: an uncommon problem with a common presentation. Indian Heart J 55(6): 655-657.

14. Maresta A, Varani E, Balducelli M, Vecchi G (2002) Spontaneous coronary dissection of all three coronary arteries: A case description with medium-term angiographic follow-up. Ital Heart J 3(12): 747-751.

15. Jaffe BD, Broderick TM (1994) Cocaine-induced coronary artery dissection. N Engl J Med 330(7): 510-511.

16. Ooi A, Lavrsen M, Monro J, Langley SM (2004) Successful emergency surgery on triplevessel spontaneous coronary artery dissection. Eur J Cardiothorac Surg 26(2): 447-449.

17. Klutstein MW, Tzinvoni D, Bitran D, Mendzelevski B, Ilan M, et al (1997) Treatment of spontaneous coronary artery dissection: report of three cases. Cathet Cardiovasc Diagn 40(4): 372-376.

18. Hong MK, Satler LF, Mintz GS, Kent KM, Pichard AD, et al. (1996) Treatment of spontaneous coronary artery dissection with intracoronary stenting. Am Heart J 132(1): 200-202.

19. Porras MC, Ares MA, Gill JZ (1998) Intracoronary stenting for postpartum coronary artery dissection. Ann Int Med 128(10): 873.

\section{Your next submission with Juniper Publishers} will reach you the below assets

- Quality Editorial service

- Swift Peer Review

- Reprints availability

- E-prints Service

- Manuscript Podcast for convenient understanding

- Global attainment for your research

- Manuscript accessibility in different formats

( Pdf, E-pub, Full Text, Audio)

- Unceasing customer service

Track the below URL for one-step submission https://juniperpublishers.com/online-submission.php 